\title{
NATURALEZA SALVAJE Y AGRESTE: LOS IMAGINARIOS DE LA NATURALEZA EN LA CONSTRUCCIÓN DEL CAMINO LONGITUDINAL AUSTRAL, CHILE 1976-1990
}

\author{
SANTIAGO URRUTIA ${ }^{a}$, ANDRÉS NÚÑEZ $^{\mathrm{b}} \&$ ENRIQUE ALISTE
}

\section{RESUMEN}

El artículo estudia el vínculo entre imaginarios de la naturaleza y la construcción del Camino Longitudinal Austral (Patagonia-Aysén, Chile) durante la dictadura del general Augusto Pinochet (19761990). Sin desmerecer la importancia que tuvieron las cuestiones geopolíticas en la producción material y simbólica del camino, se busca mostrar el rol que juega en los procesos histórico-espaciales la naturaleza comprendida discursivamente. En este sentido, se sostiene que los imaginarios de la naturaleza fueron significativos en la construcción de la obra vial Camino Longitudinal Austral porque, por un lado, la noción de una naturaleza salvaje y agreste y los esfuerzos realizados para dominarla mediante esta infraestructura ligada a la idea de desarrollo funcionaron como estrategia que utilizó el gobierno para legitimarse socialmente y mostrarse como una solución moderna a los problemas del país, y, por otra parte, porque estas referencias a la naturaleza se alinearon y reprodujeron un discurso de unidad e identidad nacional.

PALABRAS CLAVE: imaginarios, nación, naturaleza, desarrollo.

\section{WILD AND RUGGED NATURE: THE IMAGINARIES OF NATURE IN THE CONSTRUCTION OF THE CAMINO LONGITUDINAL AUSTRAL, CHILE 1976-1990}

\begin{abstract}
The article studies the link between imaginaries of nature and the construction of the Southern Longitudinal Road (Patagonia-Aysén, Chile) during the dictatorship of General Augusto Pinochet (19761990). Without detracting the importance of geopolitical issues in the material and symbolic production of the road, we seek to show the role that discursively understood nature plays in historical-spatial processes. In this sense, it is argued that the imaginaries of nature were significant in the construction work of the Southern Longitudinal Road because, on the one hand, the notion of a wild and rugged nature and the efforts made to dominate it through this infrastructure linked to the idea of development worked as a strategy that the government used to legitimize itself socially and appear as a modern solution to the country's problems,
\end{abstract}

\footnotetext{
Instituto de Geografía, Universidad de Buenos Aires. $\$ surrutiareveco@gmail.com

Instituto de Geografía, Pontificia Universidad Católica de Chile. aanunezg@uc.cl

Departamento de Geografía, Universidad de Chile. ealiste@uchilefau.cl
} 
and, on the other hand, because these references to nature were aligned and reproduced a discourse of unity and national identity.

KEY WORDS: imaginaries, Nation, nature, development.

\section{INTRODUCCIÓN}

Si seguimos a Cornelius Castoriadis para quien todo lo que se presenta a nosotros, en el mundo histórico-social, está indisolublemente tejido a lo simbólico (Castoriadis, 2013, pp. 186-187), pues la sociedad misma se instituye con lo imaginario que debe entrecruzarse con lo simbólico, de lo contrario la sociedad no hubiese podido reunirse (Castoriadis, 2013, p. 87), pero también con lo económico-funcional, de lo contrario no hubiese podido sobrevivir (Castoriadis, 2013, p. 87), se puede sostener que lo imaginario, tal como las prácticas concretas, resulta fundamental para comprender la historia, así como también las lógicas del poder del Estado y los grupos hegemónicos al interior de la sociedad (Baczko, 1999).

Ahora bien, gracias a Braudel, sabemos que el espacio también es un elemento fundamental para comprender la historia. En efecto, el espacio, entendido como una producción histórica y social, no solo es el lugar donde se despliegan, confrontan $e$ instituyen los imaginarios sociales, sino que al mismo tiempo es el producto de ellos y las prácticas que animan (Lefebvre, 2014). Con lo cual la llamada geografía imaginaria no se refiere a una geografía irreal o ilusoria, sino por el contrario alude a aquella configuración socioespacial de la cual somos parte cotidianamente y que está atravesada por la historia, los imaginarios y el poder (Said, 2008).

En consecuencia y en el marco de lo formulado, lo que este trabajo propone es precisamente centrarse en la dimensión política e ideológica de los imaginarios sociales respecto de la naturaleza, y su repercusión en las prácticas asociadas a la construcción de la obra Camino Longitudinal Austral en la Patagonia chilena.

En el Programa de Desarrollo del Estado de Chile (1983-1989), se afirmaba que el principal objetivo del gobierno era "Procurar alcanzar un desarrollo político, económico y social sobre la base de un claro concepto de unidad nacional, y en armonía con la comunidad internacional. Tales esfuerzos se realizarán en permanente concordancia con la seguridad nacional"
Vale decir, sin desconocer una de las dimensiones más establecidas y difundidas en torno a la ruta austral, esta es, la geopolítica, planteamos como propósito situarse políticamente en lo imaginario de las representaciones de la naturaleza para desentrañar sus estrategias de poder (Leff, 2006, p. 32), lo cual, al decir de Enrique Leff, se trata no sólo de una hermenéutica de los diferentes sentidos asignados a la naturaleza, sino de saber que toda naturaleza es captada desde un lenguaje, desde relaciones simbólicas que entrañan visiones, sentimientos, razones, sentidos e intereses que se debaten en la arena política (Leff, 2006, p. 33), para así aportar con una lectura alternativa y complementaria de la misma.

Este intento de desnaturalizar la naturaleza significa por tanto visibilizar la condición histórica de la construcción social del ambiente, discutiendo de esta manera el relato moderno según el cual la naturaleza es una realidad puramente objetiva, pasiva y totalmente independiente del ámbito humano y de su cultura. En esta lógica, aquí se intenta mostrar cuáles son los imaginarios respecto de la naturaleza de Patagonia Aysén que produjo la sociedad y sus estructuras de poder durante el régimen de Pinochet y cuál es su sentido en la transformación del territorio asociado a la construcción del Camino Longitudinal Austral.

De manera más precisa, se sostiene que (los imaginarios de) la naturaleza entendida como otro diferente, como reverso de lo humano, jugó un rol referido a la constitución territorial del Estado en el contexto del proyecto autoritario de reconstrucción nacional al vincularse con cierto discurso del desarrollo y la unidad nacional ${ }^{1}$, ya que según la visión oficial de la época, la nueva

(Gobierno de Chile, 1983). El mismo documento expone que el desarrollo se entiende "no sólo como un proceso de crecimiento económico, sino además como una evolución que se traduzca en una efectiva mejoría social" para lo cual se veía necesario implantar el "principio de subsidiariedad" que supone la "existencia de un sector privado con iniciativa y el derecho a la libre acción" 
naturaleza surgida y expuesta al alero del avance de la obra Carretera Austral reflejaría un nuevo orden y oportunidad para la patria gracias a un re-nacer signado por el ideal del desarrollo.

De este modo, desde 1976 y hasta 1989 al menos, la construcción del Camino Longitudinal Austral fue, junto a su obra física, la expresión del relato de reestructuración moral y económica nacional fomentado por la dictadura cívico militar en su proyecto de hacer de Chile una gran Nación, fundada en la unidad nacional y en la integración espiritual de todos los chilenos (Junta Militar, 1974) y, fundamentalmente, la manifestación tangible del discurso del triunfo del humano frente a una naturaleza, entendida como adversa y salvaje en clave desarrollista. Así, ríos, montañas, valles, fiordos, hielos y sus imaginarios se transformaron en la directriz de las obras y su superación entendida como una verdadera gesta colosal de gran significado geopolítico fue comprendida como una verdadera necesidad (Von Chrismar, 1986; García, 1989).

Nuestro planteamiento invita, por tanto, a desplazar el foco puesto por

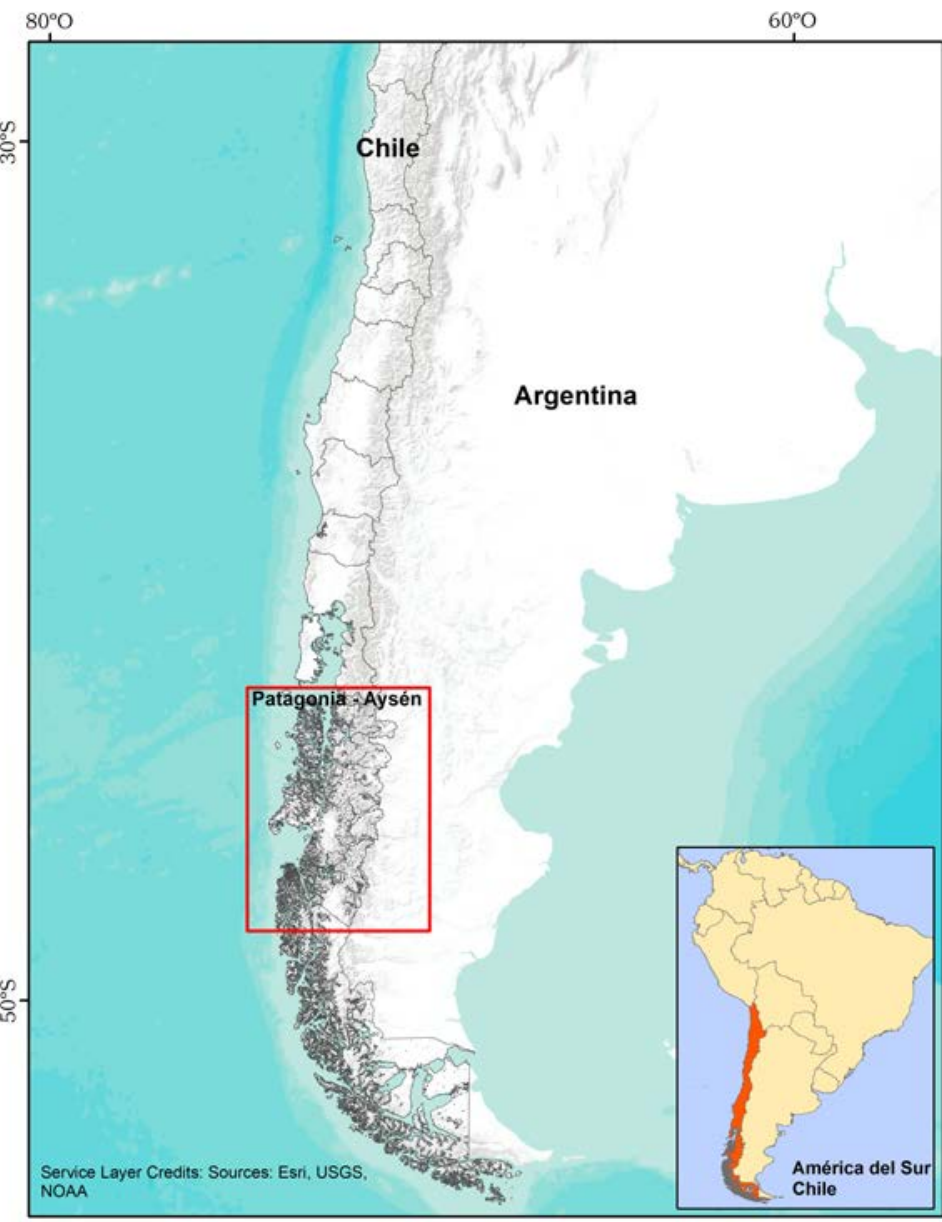

Fig. 1. Territorio de Patagonia Aysén. el enfoque tradicional en los aspectos geopolíticos y económicos de la obra vial (Peña, 1993; Van Schouwen, 1996; Krebs, 1997; García, 1997; Vásquez de Acuña, 1999) para preguntarse entre otras cuestiones: ¿cuáles fueron los imaginarios respecto de la naturaleza que rodeaba al Camino Longitudinal Austral?, ¿tuvieron alguna relevancia en la construcción de la ruta?, es decir, ¿qué rol jugó, en su aspecto discursivo, la naturaleza en la re-construcción nacional y en la materialización del Camino Longitudinal Austral durante los años de la dictadura? Metodológicamente se abordan

(p.18). Bajo esta óptica, el Estado tendría un rol básico en el "ámbito normativo y social" y debería velar por el buen funcionamiento del mercado, aunque en el "ámbito productivo", fuera la iniciativa privada la protagonista. Por su parte, la unidad nacional dependería, a su vez, de la seguridad nacional que, según el documento, se lograría, entre otras formas, "mediante el crecimiento

estas preguntas a partir del trabajo de fuentes documentales (documentos oficiales, prensa, decretos, entre otros) y análisis bibliográfico.

\section{EL CAMINO LONGITUDINAL AUSTRAL: PROYECTO DE PODER}

Entre 1976 y 1990 resonó más fuerte que nunca el ruido de detonaciones y de maquinaria pesada en Patagonia Aysén (Fig. 1). La proyección de un camino que uniera la región patagónica con el resto del territorio nacional en un sentido

armónico del país en sus aspectos políticos, económicos, sociales y de defensa, de manera de alcanzar una capacidad potencial disuasiva que aleje sustancialmente las eventuales amenazas que atentan contra la soberanía, independencia y continuidad institucional que se ha forjado la República" (p.26). Según estas definiciones el Estado debería ser, por tanto, autoritario y subsidiario. 
longitudinal, es decir, norte-sur, era una obra que no solo modificaría de manera material y tangible el territorio, sino que también reportaría profundos impactos socioculturales o encantamientos (Harvey \& Knox, 2012) en la sociedad local, al modificar la orientación de unas movilidades que tradicionalmente habían sido transversales (esteoeste) y transfronterizas (Saavedra \& Mansilla, 2014; Amigo, 2017).

Desde el principio, la obra Camino Longitudinal Austral o Carretera Austral (Fig. 2) fue difundida a través de medios oficiales y masivos durante el período de la dictadura cívico militar haciendo hincapié en las supuestas implicancias geopolíticas de la misma. A fines de 1976, año en que se reactivarían los trabajos de construcción vial por disposición de la Junta Militar, Pinochet fue entrevistado por un medio local al cual aseguró que:

He tenido la suerte de que muchas de las cosas que se están realizando son pensamientos que tuve cuando fui profesor de geopolítica en la Academia de Guerra. Hoy veo con gran fe que aquellas líneas teóricas, aquellos pensamientos urdidos al calor de una discusión entre alumno $y$ profesor, se están materializando. Entre ellas la regionalización, Vialidad, crecimiento del hinterland hacia el sur, solidez en los extremos creando zonas francas y aperturas de vías de comunicación hacia la zona de Chiloé Continental - Aysén donde creo que puede haber una población de unos dos millones de seres ${ }^{2}$.

Dos décadas después, en el contexto de las "Primeras Jornadas Internacionales de Geopolítica Academia de Guerra" celebradas en 1997, Pinochet reafirmaba esta posición sosteniendo que uno de los más importantes sellos que trató de imprimir el Gobierno que presidí fue una clara concepción en materias geopolíticas (Pinochet, [1997] 2000, p. 91). Así, proseguía,

2 Nuestra región en la mira del Presidente: "En Chiloé-Aysén pueden vivir dos millones de seres". (27 de noviembre de 1976). El Diario de Aysén, p. 1.

3 Ruta Austral. (13 de noviembre de 1987). El Diario de en el ámbito de las modernizaciones, la reforma administrativa y la regionalización -proceso que aún continúa su evolución y perfeccionamientoson, junto con la Carretera Austral las más significativas, esta última, en tanto, respuesta al desafio presentado por la naturaleza, en una de las zonas más inhóspitas del planeta ([1997] 2000, p. 93).

En una línea similar, un reconocido exponente de la geopolítica chilena de entonces, coronel Julio von Chrismar, profesor de la Academia de Guerra y subdirector del Instituto Geopolítico de Chile, aseguraba que la Carretera Austral 'Presidente Pinochet' influye favorablemente en todos los campos de acción, adecuándose a las leyes geopolíticas y a los principios geopolíticos de carácter universal (1986, p. 35), específicamente, en el fortalecimiento de los vínculos permanentes que cohesionan a la población, transformándola en nación; en los que integran el territorio, transformándolo en país y en los que aumentan la soberanía, transformándola en un poder nacional soberano, todo lo cual facilitará que se cumpla nuestro objetivo nacional: 'Hacer de Chile una gran nación' (1986, p. 44), razones de sobra para que el ministro de Defensa Nacional, contralmirante Patricio Carvajal, asegurara al año siguiente que la Carretera Austral constituía una de las realizaciones más importantes del siglo ${ }^{3}$.

Coherente con este discurso, algunos periódicos insistieron durante las décadas de 1970 y 1980 en que esta obra era la manifestación de una voluntad trascendente de afianzar la soberanía en la Región austral ${ }^{4}$. En este sentido, se celebraba la decisión política de avanzar fuertemente en la construcción de la Carretera Austral que manifestaba la preocupación del Gobierno por resolver esta situación tan vinculada a nuestra presencia soberana en una región naturalmente poco poblada ${ }^{5}$. Asimismo, se afirmaba que su construcción permite la integración de una vasta zona que alcanza cerca de una sexta parte del territorio nacional excluyendo la Antártica que se había mantenido prácticamente aislada dentro de sí misma y del resto del territorio

Aysén, p. 3.

4 Decisión política de avanzar longitudinal. (7 de febrero de 1979). El Diario de Aysén, p. 3.

5 Ídem. 


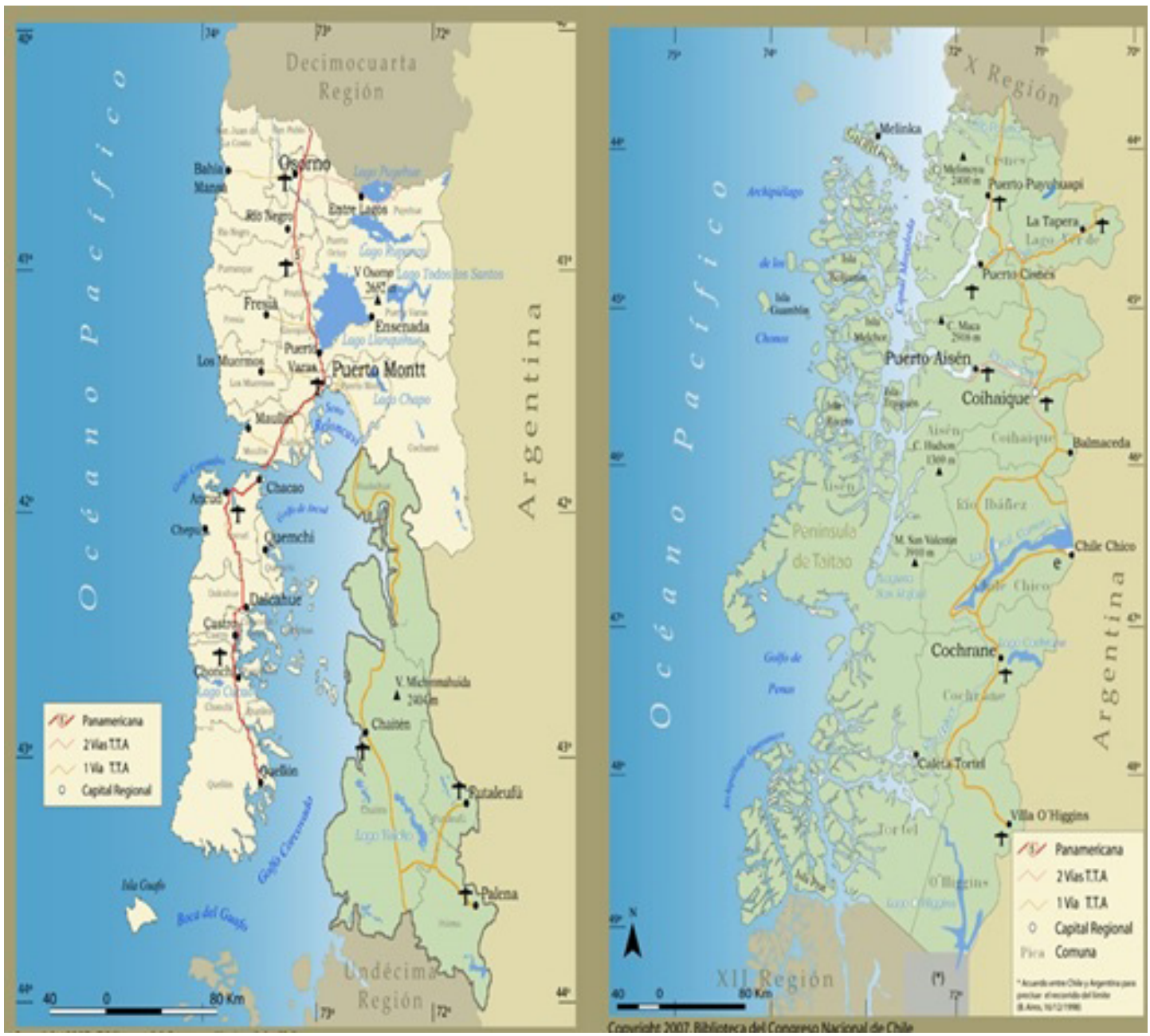

Fig. 2. Trazado de la Carretera Austral.

Fuente: Biblioteca del Congreso Nacional.

nacional ${ }^{6}$, catalogando al camino como una palanca poderosa y multiplicadora para llevar a cabo la integración de esta rica zona desde el punto de vista económico y social con sus derivaciones geopolíticas ${ }^{7}$.

En relación a una de las tensiones diplomáticas más características de la época, particularmente sensible en la región patagónica, se sostenía que la Carretera Austral será la solución definitiva que asegurará la continuidad e integridad de nuestro territorio en la parte austral, y así contribuiría a enfrentar el problema que se ha agudizado últimamente con motivos de los inconvenientes

6 Carretera Austral unió Puerto Montt con Aysén. (14 de febrero de 1984). El Diario de Aysén, p. 12.

7 Ídem. que derivan de la terquedad de las autoridades argentinas fronterizas para facilitar el tráfico denominado de 'Chile a Chile', nombre con el que se designaba al trayecto que debían realizar las personas de esta zona para abastecerse de bienes y algunos servicios utilizando obligadamente la ruta $\mathrm{n}^{\circ} 40$ de Argentina ${ }^{8}$.

De este modo, a través de diversos medios se difundió la importancia de la Carretera Austral en materia de poblamiento, soberanía, independencia respecto de las rutas argentinas en un período particularmente delicado, así como también fue presentada como fuente de renovadas perspectivas

8 El camino a Aysén. (15 de febrero de 1979). El Diario de Aysén, p. 3. 
de desarrollo, llegando a considerarse una de las más importantes y representativas obras del período. En este sentido, a finales de la década de 1980, en uno de los videos de propaganda oficial de la campaña por el SÍ se decía me gusta mi país haciendo añicos la virginidad de la undécima región y penetrándola con la Carretera Austral en busca de nuevas opciones de trabajo para hombres y mujeres de mi país ${ }^{9}$, y se instaba a apoyar en las votaciones al régimen para asegurar así su continuidad desde el supuesto que ese tipo de obras consideradas modernas solo podían llevarse a cabo a través de las lógicas características del gobierno de facto.

Lo cierto es que, a pesar de que en el plebiscito haya triunfado la opción política contraria que aseguró el retorno a la democracia, a más de veinte años de terminado el régimen de Pinochet, la Carretera Austral sigue considerándose, tal como lo hacía el ministro militar designado, La mayor obra pública del siglo XX en Chile, estimándose que en cuatro décadas la inversión fiscal en la megaobra supera los US\$1.136 millones, según expresa el diario El Mercurio en una edición de $2016^{10}$.

La naturaleza, como discurso, tuvo (y sigue teniendo) un rol importante en la construcción del relato de la ruta austral. Un argumento comúnmente usado para remarcar la importancia de la obra y el valor del régimen que la llevaba a cabo fue representar la dificultad de la vida de la región antes del camino, haciendo hincapié en la adversidad que implicaban las características de la naturaleza en esa zona. En este sentido, el ministro de Obras Públicas, mayor general Patricio Torres, en la ceremonia de inauguración del primer tramo a principios de 1982, expresaba que:

La vida de la gente era bastante diferente a la que hacen en estos momentos. Poder conversar con un vecino era una jornada, a veces, de días a caballo.

9 Franja del Sí 23 de septiembre de 1988. Disponible en: https://www.youtube.com/watch?v=RwqZjM8ithw

10 Carretera Austral suma inversión de más de US\$ 1.136 millones en cuatro décadas. (14 de febrero de 2016). El Mercurio. Disponible en: http://www.economiaynegocios. $\mathrm{cl} /$ noticias/noticias. asp? $\mathrm{id}=226428$

11 Camino Futaleufú - Puerto Ramírez inaugura hoy Presidente
Obtener las provisiones, medicinas era, a veces, también de días a caballo. El colono y sus pilcheros, a través de la selva y del barro, y cuando llegaba a la costa le seguía la lancha, el bote si el mar estaba en buenas condiciones y otra jornada igual, es decir, la vida era lentísima. Ahora, con este camino casi no existen distancias. Si antes se demoraban semanas en este trayecto, ahora es cuestión de unos pocos dias $^{11}$.

Para los organismos oficiales del Estado la obra estaba plenamente justificada pues además de este aceleramiento y acortamiento de distancias, el Camino Longitudinal Austral supuestamente eliminaría una de las principales razones del subdesarrollo que era el aislamiento determinado, desde esta óptica, por las características naturales que dificultaban la conectividad de la región. En efecto, tal como aseguraba el secretario regional de coordinación y planificación (SERPLAC), José Yuraszeck Troncoso, la valorización de la obra se fundaba en la idea de que toda alternativa de desarrollo para la región parte del hecho que primero debemos romper el aislamiento ${ }^{12}$.

De manera coherente, el diario La Nación publicó en 1982 un estudio realizado por la Dirección de Vialidad del Ministerio de Obras Públicas, en el que se afirmaba que el vasto sector que constituye la Región de Aysén ha estado históricamente aislado del resto del país y, aún, carente de comunicaciones en su propio territorio a causa de su difícil morfología geográfica, geológica y climática ${ }^{13}$, por lo cual consideraba aquella secretaría de Estado que era imprescindible seguir avanzando con los trabajos de la Carretera Austral, lo cual implicaba atravesar zonas vírgenes, rocas vivas y montañas impenetrables que dan a estas labores un carácter de aventura propia

Pinochet. (23 de febrero de 1982). La Nación, p. 1.

12 Romper el aislamiento para lograr desarrollo y progreso regional. (24 de marzo de 1979). El Diario de Aysén, p. 3.

13 Visión del Presidente Pinochet. Integración de la regional de Aysén a desarrollo nacional. (24 de febrero de 1982). La Nación, p.6A. 
de los descubridores de tierras nuevas con la consiguiente dotación de audacia y de imaginación que ello involucra ${ }^{14}$.

Por tanto, persistiendo en el uso del lenguaje épico que históricamente ha acompañado el avance del aparato estatal, mercantil y militar en la Patagonia (Bascopé, 2009), las referencias a la naturaleza que rodeaba el camino tuvieron, en este contexto, un sentido estratégico concreto: demostrar que esta moderna obra, símbolo de desarrollo, fue posible solo tras la superación de la naturaleza gracias a la voluntad y decisión de un gobierno pragmático personificado en el general Pinochet. De ahí estas emotivas palabras vertidas en la inauguración oficial del tramo Puerto Montt Cochrane del camino austral en 1988:

Hoy cuando vemos cumplido un sueño acariciado por años, cuando sólo el canto del hacha y el martillo del colono de ayer se escuchaba en la inmensidad y soledad de esta Patagonia, cuando la naturaleza salvaje y agreste parecía no ceder para dar paso a la vía y al progreso, la visión de un hombre, de un soldado, ha vencido nuevamente en una lucha tenaz, constante, fuerte e inteligente y aquello que parecía imposible es hoy una realidad ${ }^{15}$.

Este discurso se basaba en dos grandes supuestos. Por un lado, la afirmación de que el régimen era pragmático y apolítico y no se dejaba influenciar por el engañoso populismo o la demagogia (Von Chrismar, 1986). En este sentido, a la hora de sopesar las acciones del régimen en esta área, el general Pinochet afirmaba que la magnitud del desafío que presenta el desarrollo de esta zona ahuyentó a nuestros políticos tradicionales porque los gobiernos partidistas solo se interesan por los votos y los planes de desarrollo son muy costosos, en tiempo y recursos ${ }^{16}$, razón por la cual la región había vivido condenada al subdesarrollo hasta que una nueva visión se impuso en la conducción del Estado. Visión renovada que suponía, según sus propias palabras, la intervención científica

14 Ídem.

15 Ruta Austral es una realidad. (4 de marzo de 1988). El Diario de Aysén, p.4.

16 Prioridad seguirá siendo la carretera austral. (10 de diciembre de objetivos realistas, con metas nacionales, en sustitución de los ideologismos teóricos ensayados y fracasados, en su totalidad, en nuestro país ${ }^{17}$. De este modo, el régimen autoritario se auto-presentaba como una solución moderna en contraposición al estancamiento, pobreza y subdesarrollo en el que, según esta óptica, se encontraba el país en los años previos a su llegada al poder.

Del otro lado, y afirmándose sobre una mirada y comprensión de una naturaleza independiente de la sociedad, y más aún, sobre la idea que la evolución de la segunda depende del dominio/superación de la primera, la obra vial se valoraba positivamente en tanto superación o lucha contra la naturaleza. En este sentido,

(...) La carretera longitudinal austral, por su carácter de gesta colosal ejecutada sobre una naturaleza particularmente adversa e inhóspita, trascenderá en el tiempo. Por el hecho de haber horadado la roca y removido la tierra con el fin de abrir una senda para potenciar el desarrollo social y económico, esta hazaña tendrá la permanencia de las grandes realizaciones del hombre (García, 1997, p. 42).

De modo tal que razón y naturaleza se presentaron como dos extremos opuestos: razón geopolítica de uno y naturaleza salvaje del otro. Por ello, desde esta lógica, el camino austral era una gesta heroica para el proceso de consolidación del territorio del Estado: Debieron transcurrir casi 135 años para que se intentara emprender -definitivamente- la tarea de consolidar el austro chileno con el núcleo vital del país (García, 1989, p. 52). Más aún, desde este mismo lenguaje geopolítico, el camino austral fue representado como una infraestructura estratégica y necesaria para asegurar la seguridad nacional y vitalidad del Estado que facilitarían el supremo objetivo de hacer de Chile una gran nación, por lo cual la obra debía enorgullecer no sólo a nuestro supremo gobierno que la resolvió, planificó e impulsó, sino a todos los chilenos (Von Chrismar, 1986, p. 42).

de 1984). El Diario de Aysén.

17 Discurso de Pinochet. (12 de abril de 1975). El Mercurio, p. 27. 
En definitiva, el camino austral sería la infraestructura que permitiría sacar a Aysén de la condición de frontera interior a la que el mismo régimen la había relegado (Pinochet, 1993) ${ }^{18}$. Es en este desenvolvimiento de discursos que la naturaleza fue comprendida como otro radical con lo cual las prácticas destinadas a su control y sometimiento (como necesidad geoestratégica o como recurso natural) se legitimaron. De este modo, en el contexto de construcción de la ruta austral la atención prestada a la naturaleza que rodeaba la obra que se ejecutaba fue relevante. Más específicamente, a la par de los trabajos de edificación de la vía, se movilizó una serie de imaginarios respecto de la naturaleza circundante que, como veremos, construyeron la narración de la gran obra en el marco de un Estado que se veía conquistando nuevos territorios para sí.

El Camino Longitudinal Austral, según el general Pinochet, es parte de un plan de colonización perfectamente meditado, perfectamente estudiado porque tenemos que cubrir los espacios vacíos ${ }^{19}$. Es decir, la proyección de la reestructuración nacional bajo los términos de la dictadura supuso en Patagonia Aysén superar la condición de frontera interior y poblar el espacio vacío, pero también, y no menos importante, vencer a la naturaleza salvaje para dar paso a una naturaleza ordenada y controlada que fuese reflejo y valorización del desarrollo y unidad nacional. Por lo tanto, desde este punto de vista, la ruta austral más que una obra puramente técnica, ingenieril, vendría a ser expresión de un proyecto de poder.

\section{REFUNDAR LA NACIÓN:}

\section{LA NATURALEZA COMO ESCENARIO DE ORDEN (Y BELLEZA) PARA EL DESARROLLO}

El orgullo se sintió con fuerza en el ámbito oficial cuando a fines de febrero de 1982, tras una inversión de 450 millones de dólares (de la época),

18 Según Pinochet (1993), las fronteras interiores son "aquellos espacios terrestres -bajo la soberanía de Chile- no vinculados total y efectivamente a la acción del gobierno central y/o regional, donde se dificulta el desarrollo de las actividades humanas y productivas, por su distancia del núcleo vital y geohistórico del país; la ausencia de vías de comunicaciones; la influencia económica y cultural extranjera y la percepción ciudadana colectiva -en cada uno de esos espacios geográficos- de constituir un ente diferente, separado y/o se inauguró oficialmente el primer tramo de camino de unos 420 kilómetros de extensión que unía a Chaitén y Coyhaique, y la mayoría de las localidades que quedaban entre estos dos puntos. Además, se llevó a cabo en paralelo la fundación del camino transversal Futaleufú - Puerto Ramírez de 48 kilómetros y cinco puentes, $y$, por último, las dos primeras villas fundadas al lado del camino: Santa Lucía y Vanguardia.

A principios de 1988 se inauguraría otra importante etapa del camino longitudinal que tendría una cobertura mediática incluso mayor que lo ocurrido seis años antes. El tramo Puerto Montt - Cochrane fue inaugurado en marzo de 1988: eran más de mil kilómetros de trazado longitudinal que incluía tres transbordos (seno Reloncaví, canal Comau y fiordo Reñihué) siendo las expectativas eliminarlos y conseguir una conectividad netamente terrestre, aunque demorarán algunos años más por la difícil topografía que será necesario romper $^{20}$. Los tramos que efectivamente se inauguraban eran, por el norte Puerto Montt con Chaitén, y hacia el sur, Coyhaique y Cochrane, y que en total sumaban 593 kilómetros, más el tramo ya inaugurado de Chaitén - Coyhaique y los caminos transversales.

Estas inauguraciones marcaban un hito importante en la historia de la conformación territorial del Estado nación en el austro chileno. Por ello, la misma publicación expresaba que el camino austral significaba un acontecimiento trascendental no sólo para nuestra región sino también para el país, que logrará por primera vez en su historia llegar desde Santiago por tierra hasta el confín patagónico al sur del Lago General Carrera ${ }^{21}$. En este sentido, el Camino Longitudinal Austral como infraestructura que rompería con la condición de frontera interior iba aparejada a un dispositivo clave para comprender y leer esa austral región en el marco de la nación, a saber, la historia (Núñez et al. 2014).

postergado del resto de la población nacional y que no alcanza a disfrutar del bienestar general debido a factores geográficos adversos".

19 Presidente Pinochet: "quisiera abrazarlos a todos y saber cuáles son los problemas". (26 de marzo de 1979). El Diario de Aysén, p.1.

20 El jefe de estado en marzo cubrirá la ruta austral. (5 de enero de 1988). El Diario de Aysén, p. 4.

21 Ídem. 
Los eventos inaugurales iniciaron en Puerto Montt con el estreno de un monolito conmemorativo que daba origen a la ruta austral y se le conoció como kilómetro cero, para luego comenzar el recorrido oficial por el camino visitando ciudades $y$ poblados estratégicos donde se realizaron distintas ceremonias de inauguración. La gira fue de seis días por las regiones de Los Lagos y Aysén, recorriendo centenas de kilómetros de camino hasta la ciudad de Cochrane, punto más austral hasta donde unía -transbordos incluidos- la obra vial.

Además del tramo Puerto Montt - Cochrane se inauguraron en estas fechas trabajos de pavimentación en la principal vía caminera y una de las más antiguas de la región: la que une Puerto Aysén con Coyhaique (capital regional). Según el ministerio de Obras Públicas los números oficiales indicaban una Red Vial de aproximadamente $2.400 \mathrm{~km}$ que incluían el trazado longitudinal más los caminos transversales, y la construcción de 118 puentes definitivos que sumaban una longitud total de 4.720 metros lineales sobre una superficie de aproximadamente $135.000 \mathrm{~km}^{2}$. Entre 1973 y 1988 se habían invertido \$37.500.000.000 de la época y se consideraba que el avance físico representaba el 86\% de lo estipulado (MOP, 1988).

El sábado 5 de marzo de 1988 Pinochet terminó su recorrido de inauguración. En la ceremonia oficial el brigadier Fernando Hormazábal, jefe del Comando de Ingenieros del Ejército que estaba a cargo del Cuerpo Militar del Trabajo, una de las instituciones, junto con la Dirección de Vialidad del Ministerio de Obras Públicas, más importantes en la construcción del camino austral, lo felicitó por la obra refiriéndose a ella como serpenteante hilo vital que se abre con fuerza entre abismos, bosques y selvas, cruzando ríos y mallines, venciendo las rocas y que se yergue vigoroso mirando desafiante los hielos más australes ${ }^{22}$. Dicha frase retrata alegóricamente la idea que levantó la oficialidad castrense frente al camino y su naturaleza circundante: el Camino Longitudinal Austral era una infraestructura que racionalizaba un territorio considerado lejano $e$ inhóspito y que, por lo mismo, se imponía a una naturaleza que era considerada una dificultad para

22 Feliz recorrido inaugural de la Carretera Austral Presidente Pinochet (7 de marzo de 1988). El Diario de Aysén.

23 Visión del Presidente Pinochet. Integración de la regional el desarrollo. La ruta austral, por tanto, activaba un nuevo orden, un paisaje del desarrollo

(...) de una belleza indescriptible en que es dable observar picachos de nieves eternas que limitan con el cielo de un azul puro como también faldeos de asombrosa variedad de follajes de las más diversas tonalidades de colores verdes, cuyas quebradas dejan deslizar vertientes que llegan a ríos de caprichosas conformaciones que se extienden y enmarcan en valles de una hermosura que impacta al ojo humano y que justifica cuanto pueda hacerse para su incorporación orgánica a la patria ${ }^{23}$.

De manera más radical esta idílica naturaleza no solo embellecía el discurso del desarrollo que el camino austral sembraba en este territorio, sino que se actualizaba como semilla para un nuevo Chile en el marco ideológico de la dictadura. En este contexto, en forma consecuente con la relación entre el Camino Longitudinal Austral y la nueva (y bella) naturaleza abierta al desarrollo, esta ruta se fue representando como una obra que impulsaría el turismo en la región gracias a que permitiría el fácil acceso a turistas para que pudieran disfrutar de las, precisamente, bellezas naturales de la región. Podríamos decir, por tanto, que el turismo sirvió como catalizador que permitió confundir en el imaginario social el relato de una naturaleza bella atravesada por el discurso del desarrollo. Según Lefebure, con el turismo "Los ocios, comercializados, industrializados, institucionalmente organizados, destruyen esa 'naturalidad' de la que se hace cuestión para traficarla y traficar", de modo que, aún siendo valorada por aquellos rasgos que dan cuenta de la no intervención productiva, "la naturaleza entra en el valor de cambio y en la mercancía; se compra y se vende" (1978, p. 138).

En definitiva, tras el ruido de las máquinas, las excavaciones, las detonaciones e incluso las vidas de algunos quienes conocieron la muerte en los trabajos de construcción, el camino propició la conversión de la naturaleza salvaje y agreste en

de Aysén a desarrollo nacional. (24 de febrero de 1982). La Nación, p.6A. 
un escenario estético y turístico para el consumo del paisaje.

De hecho, ya en 1978 se exponía y resaltaba la necesidad de capitalizar la naturaleza acorde a su enorme potencial estético: Así la existencia de doce parques nacionales $y$ diecinueve reservas forestales, confirma el hecho de que esta región es una fuente potencial de recursos turísticos de primer orden, mientras, las grandes extensiones de bosque nativo, sus complicados sistemas fluviales y lacustres, el campo del hielo patagónico, la abundante riqueza de la fauna marina, son los grandes rubros que conforman este potencial de recursos naturales ${ }^{24}$.

En una lógica similar, ese mismo año se reproducen las anotaciones de un supuesto turista en un viaje imaginario por esta vía que aún estaba incompleta:

A partir de 1980 el viajero que desde Chaitén se dirija por tierra hasta Coyhaique, transitará una ruta jamás soñada por chileno alguno. Le significará viajar por un longitudinal de camino mejorado que atravesará montañas, bosques y valles, bordeará el mar, volcanes $y$ fuentes termales; penetrará en pueblos aún no constituidos, pero que aparecerán como por encanto al ritmo del progreso para dar albergue a miles de habitantes, y después de cruzar ríos caudalosos arribará al corazón del hoy todavía prometedor Aysén, luego de haber vivido un espectáculo soberbio y maravilloso, en una sucesión de imágenes naturales, quizás única en el mundo ${ }^{25}$.

Este relato que mezcla tanto las descripciones de una naturaleza prodigiosa, edénica, estéticamente maravillosa con la promesa de unas riquezas invaluables, de ciudades prósperas y opulentas, remite al antiguo mito de la Ciudad de los Césares que forma parte de la narración histórica de una región que tradicionalmente ha sido mirada desde el núcleo hegemónico del Estado como alejada, extraña y desconocida, pero

24 Futuro turístico de Aysén. (2 de septiembre de 1978). El Diario de Aysén, p. 3.

25 Mañana en Cisnes. SE visitará las obras del Longitudinal. (6 útilmente rica y valiosa (Núñez et al. 2017). Diez años después, dicha situación se representaba como un hecho real $e$ indiscutible gracias al camino austral:

Relevancia especial tiene para el turismo de Aysén la obra del Camino Longitudinal Austral, eje integrador que ha permitido incorporar a la oferta turística regional una gran variedad y cantidad de recursos turísticos cuya calidad resulta ser la principal motivación de extranjeros y nacionales que buscan disfrutar de un espacio natural libre de contaminación en el que se mezclan visiones de ríos, lagos, montañas, glaciares, islas, canales $y$ fiordos, vida silvestre y exuberante vegetación ${ }^{26}$.

Como exponen los documentos citados, la configuración discursiva de una naturaleza disponible al turista gracias al camino austral fue el eje de esta actividad consolidada décadas más tarde, que legitimaría, a su modo, las prácticas de apropiación de la naturaleza sometida al discurso del desarrollo que de hecho el mismo Camino Longitudinal Austral desplegaba. Sin embargo, esta no fue ni la única fuente de referencias ni la única práctica que animó este tipo de imaginarios que enfatizaban la belleza natural de Aysén.

En 1982, es decir, el mismo año en que se inaugurara el primer tramo de la ruta austral, se celebró la primera versión del entonces llamado Rally Austral Presidente de la República, el cual había trazado su hoja de ruta entre Puerto Cárdenas (X Región) y Coyhaique (XI Región): unos aproximadamente 400 kilómetros que tenían la peculiaridad y relevancia de pasar por la vía abierta recientemente. La competencia había sido organizada por la Federación Chilena de Automovilismo y auspiciada por la Compañía de Petróleos de Chile (COPEC), ambas instituciones claves en el desarrollo del deporte tuerca en Chile. Según Sergio Santander, quien por entonces figuraba como presidente de la Federación, el principal propósito de la competencia era dar a

de febrero de 1978). El Diario de Aysén, p. 3.

26 El despegue turístico de Aysén. (1 de marzo de 1988). El Diario de Aysén, p. 3. 
conocer la obra recién estrenada que daba soporte al evento deportivo y las características naturales de la zona donde se construyó ${ }^{27}$.

Además, este motivo turístico estaba cruzado por un fuerte sentido colonizador -coherente con la obra inaugurada- pues esta competencia tenía, según la publicación, como estímulo y premio para el ganador una isla en la zona austral, en el contexto en que, según el mismo Santander, el Camino Longitudinal Austral era un esfuerzo inmenso digno de destacarlo, ya que beneficia a una zona espectacularmente bella y que ha de devolverle al país toda la inversión que el Gobierno realice en Aysén ${ }^{28}$.

Este tipo de competencias se celebró irregularmente, aunque no por eso dejó de generar bastante expectativa para la opinión pública, tal como queda expresado en la prensa nacional de la época. Seis años después, meses previos a la inauguración del tramo Coyhaique - Cochrane de marzo de 1988, se gestionaba una nueva edición del Rally Austral que pasaría esta vez por los nuevos trechos de la ruta. En relación a los propósitos y alcances de esta carrera, una nota periodística afirmaba que permitirá a los chilenos recorrer los imponentes parajes de nuestra región muchas veces postergada o irremediablemente olvidada ${ }^{29}$.

Complementaria a este tipo de actividades, durante la década de 1980, se realizó a lo largo de Chile una serie de exposiciones que contenían información turística sobre el camino austral y su naturaleza circundante. En una de estas muestras realizada en 1988 sobre una de las calles más importantes de Coyhaique, la capital regional, se exhibían mapas, fotografías, elementos de trabajo, maquetas, elementos con que rompieron los trabajadores las montañas y abrieron bosques construyendo más de mil kilómetros de la Carretera Austral ${ }^{30}$.

Cabe señalar que ninguna de estas actividades que pretendian realzar las bellezas naturales de la región estaban desvinculadas del proceso de apropiación y racionalización del ambiente que estaba llevando a cabo el Camino

27 Mañana se dará la partida al rally Austral "Presidente de la República”. (26 de febrero de 1982). La Nación, p. 2B.

28 Ídem.

29 El automovilismo deportivo y el rally carretera austral. (23 de
Longitudinal Austral. De hecho, al tiempo que estas actividades colaboraban en la consolidación de los imaginarios de la belleza natural de Aysén, también naturalizaban las relaciones y estructuras de poder en este nuevo paisaje del desarrollo (Nogué, 2005).

\section{RE-CONSTRUCCIÓN NACIONAL Y CARRETERA AUSTRAL PRESIDENTE AUGUSTO PINOCHET: UNA NUEVA NATURALEZA PARA CHILE}

Estudiando la importancia de las interacciones y representaciones humanas sobre el ambiente, en su libro clásico, David Arnold demostró que la naturaleza no puede reducirse a una realidad tangible sobre la que se desarrollan las sociedades a lo largo del tiempo (Arnold, 2000). Siguiendo esta línea y desde una perspectiva más crítica que presta atención al aspecto ideológico y político que subyace a aquellos imaginarios de la naturaleza, la historia ambiental y ecología política con perspectiva latinoamericana promovida por autores como Arturo Escobar, Héctor Alimonda, Enrique Leff o Germán Palacio invita a cuestionarse los soportes de la racionalidad moderna referida a la naturaleza en tanto ella sería, en el fondo, el sustento ideológico que condiciona la actual crisis ambiental al promover la imagen de una naturaleza totalmente separada y distinta de la sociedad, cuya razón de ser era (y es) la de servir al desarrollo de la sociedad humana (Nouzeilles, 2002). Incluso autores como Erik Swyngedouw (2011) han insistido que la Naturaleza, así con mayúscula, como concepto absoluto y ahistórico, fuera del relato moderno no existe sino, en definitiva, distintas naturalezas que son apropiadas, transformadas y significadas por las sociedades a lo largo de la historia.

En otro clásico, y siguiendo la línea de los imaginarios, Benedict Anderson (2007) ha subrayado la importancia de los imaginarios respecto del territorio y la naturaleza en la construcción de la comunidad imaginada que constituye la nación. Esta perspectiva es continuada por Bernard Debarbieux (2010), quien

\footnotetext{
marzo de 1988). El Diario de Aysén, p. 3.

30 Se exhibe Carretera Austral en paseo peatonal Condell. (29 de febrero de 1988). El Diario de Aysén, p. 1.
} 
propone que los imaginarios de la naturaleza han tenido un rol protagónico en la constitución histórica de los Estado-nación. Según él, desde dos perspectivas diferenciadas, aunque perfectamente complementarias. En primer lugar, en la naturalización de la nación; es decir, atribuyendo a características del ambiente de la nación ciertas cualidades de ella. En segundo lugar, mediante la nacionalización de la naturaleza; esto es, la conversión de la base natural en emblema nacional como por ejemplo los Alpes suizos o la cordillera de los Andes en Chile (Núñez et al. 2013).

Sumado a lo anterior se puede sostener que, al interior de los territorios de los Estados modernos, la forma de colonización tradicional ha sido la nacionalización (mediante procesos legales, culturales y bélicos) de las distintas comunidades (originarias o no) que los habitan y sus territorios. En paralelo a ello, la naturaleza, como referente discursivo, ha adquirido históricamente un rol protagónico en la construcción de la identidad nacional puesto que son las expresiones visibles de una relación natural entre un pueblo o nación y el territorio o naturaleza que ocupa (Cosgrove, 2002). Así en Chile, la cordillera de los Andes se transformó en nacional y adquirió la función natural de ser frontera; otro tanto con los lagos del sur o los desiertos nortinos (Núñez et al. 2013); todos ellos van configurando un paisaje nacional en que se funda la comunidad imaginada, ya que, la producción de paisajes nacionales debe contener las diversidades de la naturaleza nacional: desierto, montaña, bosques, mar, etc. (Silvestri, 2011).

En relación a lo anterior, en lo que sigue queremos mostrar cómo una naturaleza imaginada en la época como una de las áreas menos contaminadas de Chile (...) pureza geográfica, tan necesaria para el hombre de hoy (García, 1989, p. 68), sirvió como soporte en la construcción de un relato de identidad y unión nacional como parte del principio de hacer de Chile una gran nación de la dictadura cívico militar. Así, la bella naturaleza de Patagonia Aysén expuesta a partir de la apertura del Camino Longitudinal Austral hacía evidente el relato de la re-construcción de la patria mediante la incorporación al imaginario social de un nuevo paisaje (en paralelo a la invisibilización del terror y la violencia ejercida por los aparatos de Estado).
En efecto, como se ha venido sosteniendo hasta ahora, la Carretera Austral es una obra que trasciende por mucho su aspecto puramente físico, por el contrario, creemos que puede ser comprendida más bien como un proceso históricoespacial con un marcado propósito políticopropagandístico en tanto ella abriría un nuevo espacio geográfico para que, entre otras cosas, su naturaleza pudiera cobijar un renovado sentimiento de unidad nacional que, según el discurso oficial, fue quebrada e interrumpida por el proyecto socialista de la Unidad Popular (1970-73). Es decir, esta transformación de una naturaleza inicialmente considerada salvaje y agreste a una bella tuvo que ver, en paralelo a su apreciación vinculada al discurso del desarrollo, con la apropiación de ella como paisaje que resaltara y promoviera una identidad nacional, en el contexto del proyecto "refundacional" de la dictadura cívico militar (Jara, 2011).

Por lo tanto, el propósito en la producción de estos imaginarios de la naturaleza fue otorgarle un valor trascendental a la conquista de Aysén mediante el camino austral para que contribuyera a fortalecer una suerte de nacionalismo paisajistico, en tanto la admiración de las bellezas de la naturaleza constituye una forma particular de nacionalismo de la vida cotidiana al que adscriben personas de todas las sensibilidades ideológicas (Booth, 2010, p. 11).

Esta propaganda nacionalista que resalta lo supuestamente natural de Patagonia Aysén se enmarca así en una fase específica de la política de comunicaciones del régimen autoritario que fue transmitida a través de distintos soportes en lo que Giselle Munizaga describe como la segunda etapa de la política comunicacional del régimen y que comenzó, a grandes rasgos, en la década de 1980. Aquella que, después de la fase negativa y defensiva de guerra contra la propaganda e ideología marxista, se plantea como objetivo la integración social y el control social, superando las metas puramente negativas de la etapa de estabilización (Munizaga, 1988, p.23).

En este sentido, se puede sostener que, en el fondo, a través del despliegue discursivo en torno al Camino Longitudinal Austral y su naturaleza circundante (de la naturaleza salvaje y agreste a la bella naturaleza en orden con el desarrollo) 
el régimen militar figuraba la autoimagen de su propio deber histórico: tras un período caótico, de pobreza, de conflicto social con el que representaba el período de la Unidad Popular, este gobierno vendría a hacer de Chile una gran Nación descubriendo y configurando una nueva naturaleza para el país. De este modo, la naturaleza así representada, no solo renegaba de un pasado sino que de cierto modo también ocultaba un presente (de violencia, crisis y desaparición).

En este caso, es interesante señalar que el uso político ideológico que se le da a los imaginarios de la naturaleza ya no opone lo salvaje y agreste al desarrollo, sino que lo natural se asocia con lo originario y lo idílico: En esta región, la naturaleza reúne sus mejores encantos; tupida vegetación, ventisqueros, témpanos flotantes, islas, fiordos, canales y cordilleras. Numerosos lagos, incontables ríos, bosques, montañas $y$ una vegetación totalmente salvaje hacen de esta región un lugar de ensueño ${ }^{31}$.

Arraigada la idea de nación a los elementos naturales del territorio, este tipo de imaginarios pretendió consolidar la idea de que la identidad nacional (y el orden social) que el régimen autoritario promovía era precisamente una cuestión natural, por tanto, incuestionable e invariable, es decir, el único sueño que podía ser soñado para la nación (Bhabha, 2010). Por todo esto, la labor de las comunicaciones masivas fue muy relevante en este proceso de configuración de sentido de lo nacional a partir de la naturaleza, donde cabría destacar el rol jugado por la denominada franja cultural en la cual se circunscriben varios programas de televisión que también tendieron a mostrar y relevar la belleza de la naturaleza de todo Chile.

Por medio de la plataforma televisiva, principal soporte comunicacional del régimen (Durán, 2012), aunque se presentaba a la audiencia una heterogeneidad de paisajes, se configuraba sobre ellos un sentido de unidad e identidad nacional que yacía en cada uno de estos cuadros que componían la naturaleza de la nación. En este sentido fueron representativas las series Al Sur del Mundo que en 1983 publicó un capítulo dedicado a esta zona llamado Aysén, la Trapananda, y

31 Turismo en la XI región. (22 de febrero de 1985). El Diario de Aysén, p. 3.

32 El Rostro de Dios. Imágenes del Fin del Mundo. (3 de junio
La Tierra en que Vivimos emitido por Televisión Nacional de Chile que, en el año 1984, dedicó dos capítulos a la ruta titulados Tras la ruta de la naturaleza: Carretera Austral.

De este modo, siguiendo a Baczko, para quien Lo que los medios fabrican y emiten más allá de las informaciones centradas en la actualidad puesta como espectáculo, son los imaginarios sociales (1999, p. 32), es decir, las representaciones globales de la vida social, de sus agentes, instancias y autoridades, los mitos políticos, los modelos formadores de mentalidades y de comportamientos, las imágenes de los líderes, etc. (1999, p. 32), la primera mitad de la década de 1980 es sumamente importante en la historia de la producción social de la naturaleza del territorio de Patagonia Aysén pues no solo fue el año de inauguración oficial del primer tramo del Camino Longitudinal Austral, sino también se suceden distintos hitos que contribuyeron en su construcción simbólica.

Sumado al rodaje de los programas de televisión comentados más arriba, ese año Jorge Alberto Polloni, publica su Reportaje geopolítico a la Ruta Austral, en el que se refiere a los escritores de la Revista Trapananda: Augusto Grosse y Antonio Horvath, que últimamente fueron condecorados por nuestro Gobierno (Polloni, 1982) y también al rol jugado por la Sociedad Chilena de Historia y Geografía en la difusión de la obra.

Desde el ámbito de la fotografía, estos imaginarios de una naturaleza nacional o nacionalismo natural fueron (re)producidos por George Munro quien también en 1982 publicó su primer libro (declarado al poco tiempo material didáctico para las escuelas por el Ministerio de Educación mediante decreto $\mathrm{N}^{\circ} 168$ de 1982) sobre el Camino Longitudinal Austral que con las imágenes de su naturaleza circundante tenía como propósito establecer, según él mismo declarara años más tarde, una soberanía sin $\operatorname{armas}^{32}$. En general sus obras dedicadas al camino austral resaltaban tres cosas: la belleza natural de la zona por donde transcurría el camino, la gesta heroica de construcción del camino y el significado

de 2001). El Mercurio. Disponible en: http://diario. elmercurio.com/detalle/index.asp? $\mathrm{id}=\{07 \mathrm{a} 2 \mathrm{~b} 45 \mathrm{a}-3870$ 4594-8f98-ff1a580e09be\} 
en términos de unión e identidad nacional que representaba esa naturaleza ahora abierta gracias a la ruta austral.

Estos aspectos fueron bien resumidos por el periodista y escritor Juan Gana, cuando, en una dedicatoria del libro de imágenes editado entre 1989 y 1990 por George Munro (Fig. 3), escribía: Pero seamos positivos: aún tenemos Paraíso/ El Paraíso de verdad está aquí, en Chile, en la costilla central de América Latina, rumbo al Polo Sur/ Y lo fantástico es que a nuestro Edén, abierto por la Carretera Austral, se puede entrar por aire, mar o tierra (Munro, 1990, p. 55).

Los imaginarios que representan la naturaleza como un edén terrestre no son una excepción de este lugar y aparecen asociados a distintas áreas de Chile, constituyendo en su conjunto parte importante del acervo cultural $e$ identitario en relación a la naturaleza y la nación. En efecto, esta actitud está largamente asentada en la tradición nacional, que debido a circunstancias históricas particulares que provienen desde el siglo XVIII ha tendido a promover la imagen de este territorio como un espacio bendecido por la naturaleza (Sagredo, 2010).

Ahora bien, lo interesante de notar en relación a nuestro estudio es que las referencias a este paisaje natural o prístino capaz de proyectar la unidad e identidad nacional paradójicamente fueron apareciendo mientras esta misma naturaleza iba siendo apropiada, racionalizada y transformada mediante la construcción del camino austral. Con justa razón se puede decir que nunca antes se había pensado tanto en el paisaje natural como entonces, momento clave en su proceso de transformación y puesta en valor (Berque, 2009). Como hemos mostrado, esta paradoja es fácilmente reconocible en nuestro caso pues mientras más se luchó por combatir y dominar la naturaleza salvaje y agreste para llevar a cabo la obra del Camino Longitudinal Austral, paralelamente se fue instalando la imagen turística y paisajística que hacía especial énfasis en las características naturales de esta zona.

En concreto, aparecieron numerosas vías de difusión que daban cuenta de esa aparente paradoja, como por ejemplo la Revista Tour que llegó a definir esta región como la 'reserva de Chile' en razón de las posibilidades futuras de sus recursos naturales, tanto forestales como agrícolas, ganaderos, pesqueros y mineros (Revista Tour, 1985, p. 30), al tiempo que la representaba como un mundo de belleza natural sin parangón. Cascadas que se abren en dos o tres saltos, ríos de gran caudal, inmensas

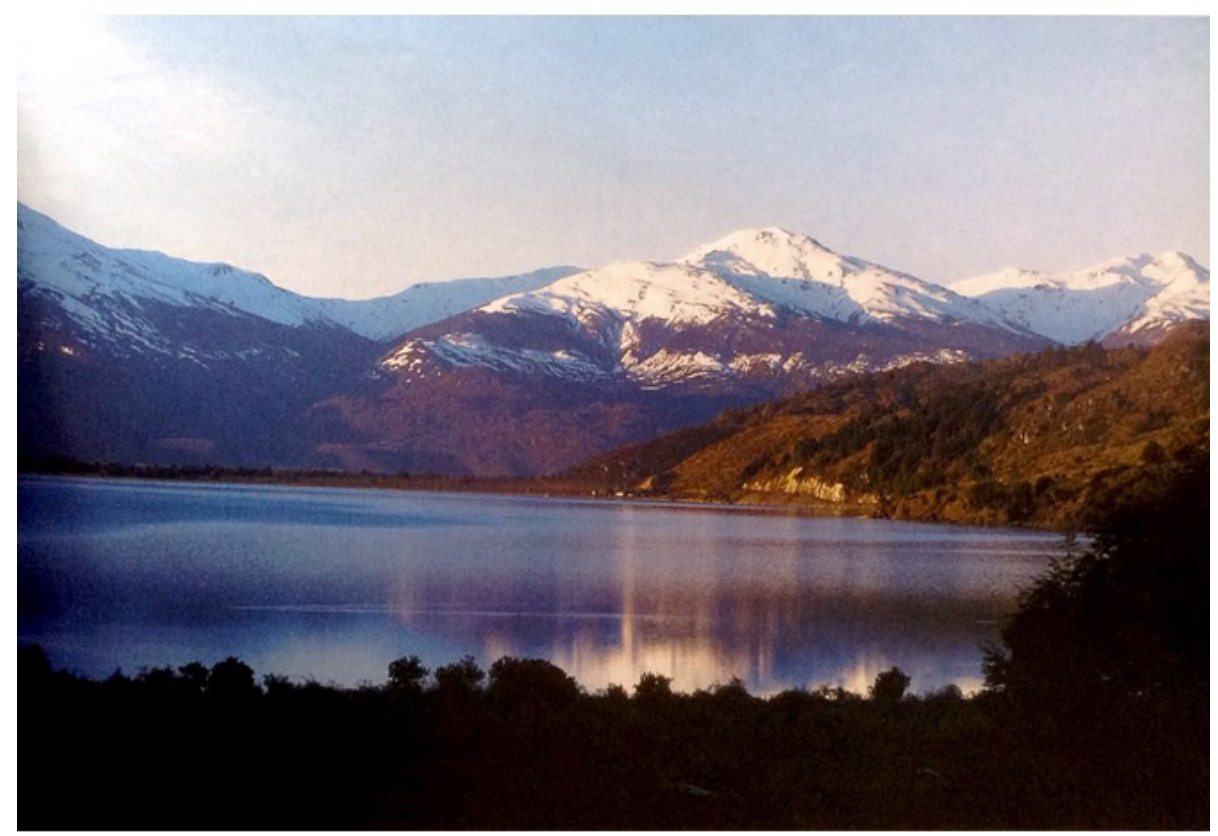

Fig. 3. Lago General Carrera

Fuente: Munro, G. (1990). El paraíso está aquí. Santiago de Chile: Instituto Geográfico Militar. 
selvas vírgenes y lagunas en que se deshacen los glaciares, son elementos corrientes del paisaje.

En definitiva, mientras se ejecutaba una importante transformación territorial determinada por los trabajos de construcción de la ruta austral que se presentaba ligada al desarrollo, en paralelo se promovía la imagen de su entorno natural como lugar que cobijaba la identidad nacional donde se encontrará fiordos y canales de silenciosa belleza y también ventisqueros, como el de San Rafael, y cascadas de hermosura sin igual, enormes extensiones de lujuriantes selvas vírgenes y lagunas, montañas, hielos, flores... La Naturaleza toda vestida de gala, en más de $100.000 \mathrm{~km}^{2}$ de maravilla (Revista Tour, 1987).

Independiente del imaginario específico en relación a la naturaleza, cada una de estas aprehensiones y apropiaciones de sentido otorgadas revela siempre que está operando en ellas una alteridad fundamental, un distanciamiento ontológico entre humano y naturaleza, común a las sociedades modernas occidentales (Descola, 2012). Dicha perspectiva ha sido también desarrollada por el pensamiento decolonial para el cual la modernidad ha implicado una colonialidad de la naturaleza (Alimonda, 2011).

En definitiva, los imaginarios de la naturaleza de este territorio han sido diversos, e incluso opuestos durante el proceso de construcción del Camino Longitudinal Austral y su relato es indivisible de los intereses que se buscaban con ellos. En un mismo documento podía ser representada como una zona de una belleza indescriptible ${ }^{33}$ con el fin de cobijar ahí un sentimiento de unidad nacional y nacionalismo paisajístico, o como una superficie aproximada de $135.000 \mathrm{~km}^{2}$ con unos 25.000 $\mathrm{km}^{2}$ de tierras aptas para la ganadería y con una de las mayores riquezas forestales potenciales del país, a lo que deben agregarse considerables recursos minerales e hidráulicos ${ }^{34}$, cuando se quería resaltar la importancia de la obra para los fines del desarrollo y el sello moderno del régimen que la ejecutaba.

Así, en el período de estudio, la naturaleza en Patagonia Aysén fue percibida y descrita simultáneamente de distintas formas dependiendo

33 Visión del Presidente Pinochet. Integración de la regional de Aysen a desarrollo nacional. (24 de febrero de 1982). La Nación, 6A. de lo que se quisiera resaltar a partir de estos imaginarios: obstáculo y desafío; belleza y paraíso; reserva económica. De cualquier modo, la naturaleza no fue un agente neutro en el devenir del Camino Longitudinal Austral sino, por el contrario, fundamentó y activó los discursos de construcción de una nueva patria y de un nuevo orden ligado al desarrollo.

En el año 1988 se podía leer en un periódico local el siguiente poema que, desde nuestro punto de vista, ilustra la fundición de los imaginarios sobre la naturaleza, Camino Longitudinal Austral, desarrollo y un nuevo paisaje nacional en la óptica oficial:

Los pies sobre la tierra,/ voy cantando/ por el cordón umbilical/ de mi Nación/ La Carretera Austral/ cruza los mares/y va en busca de rios,/ quebradas y glaciales./ El colono me espera/ con su mate y una sonrisa/ fragante a calafates./Los chicos anudan los silencios/ de bosques milenarios./ Brota la voz de Aysén llena de vida/ en un grito de fe $y$ de esperanzas/Los pies sobre la tierra,/ las manos extendidas al futuro/marchamos por la senda,/ que una gran voluntad abrió en la selva./Cordón de plata/que une ya mi Patria,/ de norte a sur,/en un fecundo abrazo./ Canta el colono/ su canción de gracias,/ al Gran Soldado/ que le dio esta dich $a^{35}$.

\section{CONCLUSIONES}

Desde la perspectiva del estudio de los imaginarios de la naturaleza que movilizó el Camino Longitudinal Austral, su historia puede ser considerada un indicio entendido como zona privilegiada que permite descifrar una realidad más amplia aparentemente impenetrable, es decir, como un punto donde se acumula una serie de discursos, valores, intereses, condiciones económicas, sociales y culturales (Ginzburg, 2008). En este caso, como indicio a partir del cual se puede comprender el rol político e ideológico que cumple la producción simbólica de la naturaleza en los procesos histórico-espaciales ligado al régimen autoritario del general Pinochet.

\footnotetext{
34 Ídem.

35 Bascuñán, Ignacio. (1 de marzo de 1988). Carretera Austral. El Diario de Aysén, p. 3.
} 
El análisis de la documentación relacionada a nuestra problemática permite comprobar que a nivel discursivo la naturaleza es un agente activo en este tipo de procesos. Para dar cuenta de ello ha sido preciso utilizar una perspectiva teórica que no

(...) trata tan sólo de adoptar una perspectiva constructivista de la naturaleza, sino política, donde las relaciones entre los sereshumanos, yentreéstoscon lanaturaleza, se construyen a través de relaciones de poder (en el saber, en la producción, en la apropiación de la naturaleza) y de los procesos de 'normalización' de las ideas, discursos, comportamientos y políticas (Leff, 2006, p. 26).

En este sentido, es importante destacar que los sentidos dados a la naturaleza están ligados a los modos de producir la vida social y los vínculos con el ambiente, por ende, son diversos $y$ se encuentran en constante disputa. En este estudio se mostró un caso particular enlazado a los grupos que encabezaron la dictadura cívica militar en Chile.

De manera más específica se dio cuenta de que el proceso de construcción del Camino Longitudinal Austral impulsó distintas maneras de representar la naturaleza y viceversa. De manera sincrónica y no como sucesión cronológica, la naturaleza fue vista como salvaje y agreste, en tanto que desafío y obstáculo para el desarrollo y por ende necesaria de dominar y civilizar según una lógica racional. A este respecto cabe retomar las propuestas del geógrafo Yi Fu Tuan cuando habla sobre las diferencias que tiene el aspecto de un espacio sin intervención y otro con intervención del humano. Según él, los primeros son de formas y perspectivas irregulares y más circulares, envolventes. Por el contrario, los espacios con intervención humana se caracterizan por las líneas rectas, las figuras geométricas (Tuan, 2007). El Camino Longitudinal Austral es efectivamente una rectificación de las perspectivas, la perforación de la geografía social de Aysén y la verticalización del territorio en tanto se hace prevalecer el sentido norte-sur por sobre la referencia este-oeste que históricamente había predominado en esta zona (Saavedra \& Mansilla, 2014).
La naturaleza también fue interpretada como una reserva, donde ella fue capitalizada fundamentalmente como recurso en base a una belleza indiscutible, perspectiva que iba acompañada de una valorización de la industria del turismo donde la naturaleza es comprendida como un bien de consumo estético y de experiencias. En todas estas perspectivas, la naturaleza fue comprendida como objeto, apartada del mundo social y que podía ser modelada por los intereses humanos. Desde ese punto de vista, se desplegó también un sentido simbólico y político más trascendente que su materialidad y que estuvo asociado a referencias patrióticas y el proyecto de hacer de Chile una gran nación.

\section{AGRADECIMIENTOS}

Los autores agradecen el apoyo de CONICYT a partir del proyecto FONDECYT $N^{\circ} 1170643$ "El discurso de la naturaleza en Patagonia Aysén: nuevos imaginarios geográficos en la producción del espacio geográfico de la nación (Chile, 1990-2016)".

\section{BIBLIOGRAFÍA}

Alimonda, H (Coord.). (2011). La naturaleza colonizada. Ecología política y minería en América Latina. Buenos Aires: CLACSO.

Amigo, C. (2017). No estamos lejos, allá están lejos. Construcción sociocultural del aislamiento. Perspectivas locales sobre aislamiento en Aysén: imaginario estatal y aislamiento como territorialidad. En A. Núñez, E. Aliste, Á. Bello \& M. Osorio (Eds.), Imaginarios geográficos y discursos de frontera. Aisén desde el texto de la nación (pp. 167-190). Coyhaique-Santiago: Nire Negro - Pontificia Universidad Católica de Chile.

Anderson, B. (2007). Comunidades imaginadas. Reflexiones sobre el origen y la difusión del nacionalismo. México: Fondo de Cultura Económica.

Arnold, D. (2000). La naturaleza como problema histórico. El medio, la cultura y la expansión de Europa. México: Fondo de Cultura Económica.

Baczko, B. (1999). Los imaginarios sociales. Buenos Aires: Ediciones Nueva Visión.

Bascopé, J. (2009). De la exploración a la explotación. Tres notas sobre la colonización de la Patagonia austral. Nuevo Mundo. Mundos Nuevos. Disponible en: 
http://journals.openedition.org/nuevomundo/56645

Berque, A. (2009). El pensamiento paisajero. Madrid: Biblioteca Nueva.

Bhabha, H. (2010). Nación y narración. Entre la ilusión de una identidad y las diferencias culturales. Buenos Aires: Siglo XXI editores.

Booth, R. (2010). El paisaje aquí tiene un encanto fresco y poético. Las bellezas del sur de Chile y la construcción de la nación turística. Revista de Historia Iberoamericana, $1,10-22$.

Castoriadis, C. (2013). La institución imaginaria de la sociedad. México: Tusquets.

Cosgrove, D. (2002). Observando la naturaleza: el paisaje y el sentido europeo de la vista. Boletín de la A.G.E, 34, 63-89.

Debarbieux, B. (2010). Los imaginarios de la naturaleza. En A. Lindón \& D. Hiernaux (Eds.), Geografías de lo imaginario (pp. 140-156). Barcelona: Antrhopos.

Descola, P. (2012). Más allá de naturaleza y cultura. Buenos Aires: Amorrortu.

Durán, S. (2012). Ríe cuando todos estén tristes: el entretenimiento televisivo bajo la dictadura de Pinochet. Santiago de Chile: Lom.

Escobar, A. (2012). Más allá del desarrollo: postdesarrollo y transiciones hacia el pluriverso. Revista de Antropología Social, 21, 23-62.

García, G. (1997). Visión geopolítica de la Carretera Longitudinal Austral. En Munro, G. La Carretera longitudinal Austral: su impacto y proyección (pp. 42-64). Santiago de Chile: Fundación Presidente Augusto Pinochet Ugarte.

Ginzburg, C. (2008). Mitos, emblemas, indicios: morfología e historia. Barcelona: Gedisa.

Harvey, P., \& Knox, H. (2012). The enchantments of infrastructure. Mobilities, 7, 521-536.

Jara, I. (2011). Politizar el paisaje, ilustrar la patria: nacionalismo, dictadura chilena y proyecto editorial. Aiesthesis, 50, 230-252.

Krebs, R. (1997). Historia de la Carretera Austral. En Munro, G. La Carretera longitudinal Austral: su impacto y proyección (pp. 19-41). Santiago de Chile: Fundación Presidente Augusto Pinochet Ugarte.

Lefebure, H. (1978). El derecho a la ciudad. Historia, ciencia, sociedad. Barcelona: Península.

Lefebvre, H. (2014). La producción del espacio. Madrid: Capitán Swing.

Leff, E. (2006). La ecología política en América Latina. Un campo en construcción. En H. Alimonda (Ed.), Los tormentos de la materia. Aportes para una ecología política latinoamericana (pp. 21-39). Buenos Aires: CLACSO.

Munizaga, G. (1988). El discurso público de Pinochet: un análisis semiológico. Santiago de Chile: CESOC.

Nogué, J. (2005). La construcción social del paisaje. Madrid: Biblioteca Nueva.

Nouzeilles, G. (2002). La naturaleza en disputa. Retóricas del cuerpo y el paisaje en América Latina. Buenos Aires: Paidós

Núñez, A., Sánchez, R., \& Arenas, F. (Eds.). (2013). Fronteras en movimiento e imaginarios geográficos. La cordillera de los Andes como espacio cultural. Santiago de Chile: RIL Ediciones y Geolibros Instituto de Geografía.

Núñez, A., Aliste, E., \& Bello, Á. (2014). El discurso del desarrollo en Patagonia-Aysén: la conservación y la protección de la naturaleza como dispositivos de una renovada colonización. Chile, siglos XX-XXI. Scripta Nova, 493, 1-13.

Núñez, A., Aliste, E., Bello, Á., \& Osorio, M. (2017). Imaginarios Geográficos, Prácticas y Discursos de Frontera: Aisén desde el texto de la nación. Coyhaique: Nire Negro.

Palacio, G. (2006). Breve guía de introducción a la Ecología Política: orígenes, inspiradores, aportes y temas de actualidad. Gestión y Ambiente, 9, 7-20.

Peña, M. (1993). Un camino llamado Chile: crónica del Cuerpo Militar del Trabajo. Santiago de Chile: Archivo del CMT.

Pinochet, A. ([1997] 2000). Visión geopolítica de Chile. Pensamiento y acción. En C. Meirelles (Ed.), Antología geopolítica de autores militares chilenos (pp. 83-101). Santiago de Chile: Centro de Estudios e Investigaciones Militares.

Saavedra, S., \& Mansilla, X. (2014). Tras las huellas de la carretera austral. Retazos de historia oral sobre conectividad en la Región de Aysén. Coyhaique: Nire Negro.

Sagredo, R. (2010). Chile: de "finis terrae imperial" a "copia feliz del edén" autoritario. El País, 12 de agosto, 2010. Disponible en: https:// elpais.com/internacional/2010/08/12/ actualidad/1281564003_850215.html.

Said, E. (2008). Orientalismo. Barcelona: Debolsillo.

Silvestri, G. (2011). El lugar común. Una historia de las figuras de paisaje en el Río de la Plata. Buenos Aires: Edhasa.

Swyngedouw, E. (2011). La naturaleza no existe! La sostenibilidad como síntoma de una planificación despolitizada. Urban, 41-66. 
Tuan, Y. F. (2007). Topofilia. Un estudio de las percepciones, actitudes y valores sobre el entorno. España: Editorial Melusina.

Van Schouwen, G. (1996). Historia del Cuerpo Militar del Trabajo. Santiago de Chile: I.G.M.

Vásquez de Acuña, I. (1999). Las vías de comunicación y transporte australes (siglos XVI al XX). Santiago: Arancibia Hns.

\section{Otras fuentes}

El Diario de Aysén, Coyhaique, 1976-1990.

El Mercurio, Santiago de Chile.

García, G. (1989). Carretera Longitudinal Austral. La respuesta a un desafío. Revista Chilena de Geopolítica, 3, 5169.

Gobierno de Chile. (1983). Programa de Desarrollo del Estado de Chile (1983-1989).

Junta Militar. Declaración de principios del Gobierno de
Chile. Santiago, marzo 11 de 1974.

La Nación, Santiago de Chile, 1982-1988.

Ministerio de Obras Públicas de Chile. (1988). Factor de integración nacional. 15 años de progreso sostenido 1973-1988. Santiago de Chile: Gobierno de Chile.

Munro, G. (1982). Carretera Austral: integración de Chile. Santiago de Chile: Eds. Servicios Promocionales.

Munro, G. (1990). El paraíso está aquí. Santiago de Chile: Instituto Geográfico Militar.

Pinochet, A. (1993). Ejército de Chile: posibles elementos a considerar en su proyección futura. Conferencia del Comandante en Jefe del Ejército el 19 de agosto de 1993.

Polloni, J. A. (1982). Reportaje geopolítico a la Ruta Austral. Santiago: Guillermo Krum S.

Revista Tour, 1985-1987.

Von Chrismar, J. (1986). Trascendencia geopolítica de la Carretera Austral 'Presidente Pinochet'. Revista Chilena de Geopolítica, 3(1), 35-44. 